\title{
Urban air pollution perception through the experience of social practices: talking about breathing with recreational runners in London
}

\author{
Antonia Hodgson, UCL, London \\ Russell Hitchings, UCL, London \\ Final accepted paper for 'Health and Place'
}

\begin{abstract}
This paper examines how interviews with outdoor recreational runners can help us understand how urban air pollution insinuates itself into the consciousness of those who may be breathing more polluted air than most. It begins by making the case for why studies of air pollution perception might turn to the subjectivities associated with taking part in relevant social practices. Then, with reference to debate about the extent to which groups of exercisers are thinking about certain aspects of what is physically happening during their exercise, we examine how outdoor recreational runners in London talk about the air that they breathe when running. We might imagine that this group would be particularly alive to urban air pollution in view of a presumed interest in physical performance and a personal history of running through various bodies of city air. However, through close scrutiny of their running talk, this paper documents how and why the suggestion of breathing polluted air is often placed beyond the realm of conscious thought for them during their runs. These findings point to particular strategies for encouraging healthy urban lifestyles and illustrate the potential of further studies on how social practices shape pollution perceptions.
\end{abstract}


Keywords: Air pollution perceptions, recreational running, social practice theory, qualitative interviewing, embodied exercise, public health promotion

\section{Highlights}

- Argues that air pollution perception research might turn to the lived experience of taking part in the social practices that put people at risk

- Develops this approach through a study of urban recreational runners in view of the health benefits of running but also the associated pollution exposure

- Presents the results of an interview study focused on the experienced breathing of recreational runners in London and how air quality features within this

- Documents how and why the suggestion of breathing polluted air is often placed beyond the realm of conscious thought for this particular group of runners

- Argues for further research on how the pollution 'perception gap' can be examined through social practices in view of a prevailing focus on residential location 


\section{INTRODUCTION}

In line with its continued growth in international popularity (Schreeder et al. 2015), recreational running has become one of the most common forms of exercise in the UK (Sport England 2017). Running can take place in a variety of environments, can be done alone or in a group, is comparatively low-cost, and requires little specialist knowledge or experience to get started (Shipway and Holloway 2010; England Athletics 2013). All this makes running an easily accessible form of exercise, particularly when finding the time to exercise in modern societies means working around what are often felt to be increasingly busy schedules (Hitchings and Latham 2016; England Athletics 2017). From a public health perspective, this is a positive trend, since the health and wellbeing benefits of regular aerobic exercise are numerous. They include reduced risk of chronic health conditions such as coronary heart disease, obesity, diabetes and stroke, as well as improving mental health by enhancing mood, self-esteem and reducing fatigue (Department of Health 2011).

Yet the environments in which people run are not always conducive to health. Urban air quality is of particular concern in this regard due to the effects of emissions from vehicles, buildings and industry. So, though running is encouraged in terms of public health, those who run in cities, and who will likely be running at traffic level, are defined as an 'at risk' group, due to their increased exposure to vehicular pollution, which in many cities is the main source of air pollution (Carlisle and Sharp 2001; GLA 2017a). Those focused on athletic impact therefore advise exercising away from the roadside wherever possible when running in cities (Carlisle and Sharp 2001; Sharman et al 2004). In the UK, London's Air Quality Network (2017) goes as far as to suggest planning to avoid outdoor exercise during high pollution events and in heavily polluted areas. However, in most cities avoiding the roadside is difficult. Furthermore, it is not at all clear whether those who seek a healthy lifestyle through regular urban running are particularly attuned to the dangers of air pollution.

This paper examines how air pollution risk is refracted through the experienced breathing of London runners. Though other cities routinely experience far higher levels, pollution has 
recently become a priority for London policymakers as it has been recognised as one of the most polluted places in the country with over 9000 people being estimated to die each year as a result of its 'dangerously' and 'illegally' poor air quality (GLA 2017b:19). We begin by arguing that studies of air pollution risk perception might usefully turn to those taking part in relevant social practices. Then we consider what existing research suggests about the extent to which runners are actively thinking about the environments through which they run. After that, with reference to debate about the value of interviews in researching the exercise experience, we argue for scrutinising how established exercise 'practices' are partly sustained by particular combinations of talk and thought. This then leads to a discussion of the findings of an interview study with recreational runners in London and a consideration of how and why the suggestion of breathing polluted air when running is often beyond the realm of conscious thought for them. We end with the implications for public health promotion before arguing for the value of further studies on how social practices shape pollution perceptions in view of a prevailing focus on residential location.

\section{LITERATURE REVIEW}

\subsection{Urban air pollution perception and the exercise experience}

As a product of modern industrial society, urban air pollution has become a significant public health hazard (D'Amato et al 2010; Wakefield et al 2001). One response from social researchers has been to explore how public 'perceptions' of this hazard can positively inform relevant policy (Bickerstaff and Walker 2001). Some of them have particularly highlighted the role of direct sensory experience in shaping perceptions, with sight and smell being particularly recognised as key sensory cues in shaping the awareness of air pollution (Bickerstaff and Walker 2001; Johnson 2012; Xu et al 2017). Johnson (2012) has,

for instance, argued that individuals rely on sensory information more than any formalised air quality data because it is seen as more reflective of their immediate surroundings. 
These studies generally centre on those who live in specific areas (Xu et al 2017; Bickerstaff and Walker 2001; Johnson 2012; Day 2007), with various studies across the world exploring how particular groups of urban residents respond to local pollution risk (see, for example, Muindi et al 2014; Zhang et al 2014; Wakefield et al 2001). This focus makes sense when living in areas with greater pollution levels will likely translate into higher exposure. However, it is not only where you live that shapes exposure but also what you do. In this respect, there have been comparatively few studies on the relationship between specific social practices and the air pollution perceptions produced by taking part in them. Badland and Duncan (2009) consider the experience of 'commuting' in Australia to argue that those who commute through 'active travel' - running, cycling and other activities linked to greater pollution exposure - are relatively unfazed by this risk. Partly because their experience is short lived, Li et al (2016) document how international tourists to Beijing are more concerned about the implications of pollution for the quality of their photographs than any personal health impacts. Others have focused on cyclists and their experience of traffic related pollution (de Hartog et al 2010; Zuurbier 2010). This work considers the cost-benefit health playoff of cycling through polluted air but does not examine the detail of the experience. So, whilst there is certainly mention in the air pollution perception literature (e.g. Saksena 2011) of how certain 'lifestyle factors', such as the amount of time spent during activities outside buildings, may influence pollution perceptions, few have looked indepth at how the experience of taking part in particular activities plays into this process.

Were we to attempt to address this oversight, outdoor exercisers represent an excellent group with which to start because exercise puts them at particular risk (Sharman et al 2004). As a person's average daily dose of air pollution can be understood as a product of average pollutant concentration and ventilation rate, the dose received will vary depending on the level of activity being undertaken as well as the environment in which it takes place (Pope et al 2011). However, the enhancement of the respiratory process associated with exercise nonetheless generally entails the increased deposition of pollutants in the lungs due to increased ventilation (breathing more deeply and frequently), the inflammation of airway cells, and the impairment of nasal clearance (Carlisle and Sharp 2001; Sharman et al 2004; Rundell 2012; Cavalcante de Sá et al 2016). Smaller particles, such as those commonly found 
in the fresh exhaust fumes that will likely be inhaled when in close proximity to road traffic are also thought especially problematic for exercisers because their size allows them to infiltrate the lungs more deeply (Rundell 2012). As a result of all this, air pollution has been argued both to decrease athletic performance in the short term and contribute to health problems in the longer term due to stress on the respiratory and cardiovascular systems (WHO 2016; Rundell 2012). However, most studies on this topic have focused on physiological impact by collecting data on matters such as blood gas concentrations, lung function and athletic performance (Sharman et al 2004; Rundell 2012; Helou et al 2012). Less has been said here about how outdoor exercisers themselves relate to air pollution.

The project on which this paper draws sought to respond to this situation through a focus on outdoor recreational runners in London. London is a city where the health impacts of air pollution are a growing concern. The size and scale of the city's road network, along with building emissions, make London one of the most highly polluted areas in the UK (London's Air Quality Network 2018). Cleaning up London's air has therefore become a priority for the Mayor of London and forms a significant part of London's newly proposed Environment Strategy (GLA 2017b). Strategies within that currently centre on cutting emissions from the most polluting vehicles with an emphasis on diesel, via the proposed Ultra Low Emission Zones and Toxicity Charge which form part of future plans to secure better air for London (GLA 2017a). This is in addition to anti-idling campaigns and strategies to promote fresh air squares, green walls and tree planting that have already been implemented by local authorities (GLA 2016). Though the pollution levels seen in this city may be lower than those found in others around the world, the health Implications of London's air quality for those who live, work and play in this city has become a topic of considerable concern.

\subsection{How recreational runners relate to their environments}

As lifestyles have become more and more sedentary in many countries, encouraging regular physical exercise in order to improve the health of populations has become an increasingly important focus of public health research (McKenna and Riddoch 2003). With this in mind, a 
number of qualitative studies have examined the recreational running experience with a view to further aiding its international growth (for example, Barnfield 2016; Hitchings and Latham 2017a; Shipway and Holloway 2010). Within this, an understanding of how it is to exercise in certain physical environments has been argued to have a valuable role in devising strategies to encourage greater participation (Hitchings and Latham 2017a).

The picture produced by this work in terms of how actively engaged runners are with their environments is, however, currently mixed. In some studies, for example, they would appear to be very aware of the environments through which they move. Lorimer, for example, sees the runner as a 'highly accomplished sensualist' (2012:83) for whom the experience of different surfaces underfoot supplies an on-going stream of information about the physical environment. Others emphasise how runners interpret various physiological effects such as those associated with injury, pleasure, pain and comfort through their physical experience of environmental engagement (Hockey 2013; Shipway et al 2012; Howe and Morris 2009). Barnfield similarly argues that urban recreational running 'is bound up with particular intensities and sensations generative of daily sense-making practices and experiences' (2016:282), noting in passing how these sensations can lead some runners to avoid areas with greater air pollution. Edensor et al (2018) also suggest that 'urban runners' may be particularly attuned to the density of obstacles by which the city is characterised, including a diversity of people, animals and objects (on this, see also Cook et al 2016). Taken together, these studies can leave the impression of a constant feedback loop between the running body, the running mind, and the material environment.

Other studies, however, emphasise how environmental features can be pushed out of the consciousness of runners. Hockey (2013) describes a mix of meditation and physical monitoring for the more experienced runner who moves into and out of states of ease, exertion and environmental engagement over the course of a training run. Hitchings and Latham (2016), when comparing indoor treadmill runners and outdoor runners in London, find that an absence of distracting environmental variation can be precisely what is valued by some runners because that absence helps them to keep going. Similarly, in developing an 
argument about how exercise should be understood theoretically, Andrews draws attention to the idea of 'running hot', namely a desirable state of 'immersement and involvement in physical activity' (2017: 210) associated with unselfconscious participation and ease of movement. In such states, environmental variation would appear to be either willfully ignored by those who run or effortlessly decoupled from their running experience. So, whilst the trend towards greater recreational running has become a topic of growing interest for qualitative researchers hoping to contribute to broader public health, the interpretations of those who have studied relevant groups of runners through these means currently differ in terms of how actively engaged with their material environments they appear to be.

\subsection{Breathing awareness and the running experience}

This paper links this discussion to air pollution perception research through a focus on how recreational runners relate to their breathing. This is a potentially challenging means of exploring environmental engagement because breathing is generally taken to involve a largely subconscious process through which air is straightforwardly inhaled into the lungs to allow respiration (Edwards 2005). In view of this apparent lack of consideration, social researchers interested in breathing have generally focussed on groups of 'aware breathers' (Macnaughton and Carel 2016:304) whose attention is, for various reasons, drawn to this basic physiological process. Lande (2007), for example, has examined the process by which particular forms of breathing are wilfully acquired by army cadets as they are recruited into a culture of composed and capable soldiering. Another example is Edwards' work on how 'yogic breathing' aims to 'calm, quieten and refresh the mind' (2005:33). Finally, and moving closer to the empirical focus of this paper, Allen-Collinson et al. (2016) have examined the experience of asthma amongst sportspeople. They highlight how exercisers, through an awareness of their breathing, become attuned to their own corporeality and that of others.

In their examination of breathlessness, Macnaughten and Carel (2016) contend that cultural studies of breathing could usefully bridge the gap between clinician and patient experience (see also Oxley and Macnaughten 2016). In this paper, we argue they may also help bridge the gap between those who encounter air pollution during particular activities and those 
who would influence them in pursuit of public health. In this respect, we would position recreational runners as a group of potentially 'aware breathers'. Paying attention to their breathing is often given as advice to athletes (Schucker et al 2009) and running at high altitudes through air with comparatively low oxygen contents is a strategy of elite runners who hope thereby to increase their overall athletic performance (Rusko et al 2004; Lundby et al 2012). Though we must be careful about extrapolating from studies of sportspeople to those who may merely enjoy the experience and effects of exercise (Hitchings and Latham 2017b), this suggests that runners might take a particular interest in how and what they breathe. Hockey argues breathing provides a 'constant and almost instantaneous feedback' (2013:133) during training runs, Edwards highlights how the strategy of focussing on breathing can encourage a positive 'dissociated thinking' (2005:35) amongst runners, and Allen-Collinson (2008) stresses how attention to the breathing of others helps in the functioning of running groups. However, before the present study, how much any of this applied to how solitary recreational runners related to urban air pollution was unclear.

\section{METHOD}

\subsection{Studying the exercise experience through practitioner talk}

In attempting to understand the lived experience of sport and exercise, many researchers have been reticent about the suitability of the otherwise common method of interviewing. Some argue that we should start by respecting the 'silence of sportspeople,' an idea which Bourdieu (1990:166) uses to highlight how practitioners may have little need, desire or ability to provide any analytical account of what they are doing. The concern here is that research methods centred on the examination of respondent talk cannot help but place undue emphasis on relatively abstract forms of conversational reasoning in ways that take analysis away from the physical responses and embodied routines that are often discussed with difficulty but clearly central to the exercise experience (see, for example, Wacquant 2004 on this). Recent examples of researchers showing a degree of reticence about the effectiveness of the interview in this regard include Nyberg's examination of the practical knowledge of skiiers, which is only 'possible to articulate to a certain extent' (2015:500) and Griffin's (2017) work on older Australians in which 'body anchored interviewing' is used as a 
means of gaining better access to the importance of embodied learning. Others include Kumate and Falcous' (2017) Judo study in which participation is thought essential to generating the truest understanding of the activity and Owton and Allen-Collinson's (2017) work considering how artistic representations of dance might usefully supplement more traditional methods by allowing the researcher to surface relevant 'body memories'.

Arguments such as these encourage exercise researchers to think quite carefully about how they understand and analyse talk, rather than uncritically turning to the interview because of its familiarity. In response, the present paper draws on recent accounts of 'social practice theory' (see, for example, Hui et al. 2017) to position combinations of thought and speech as component parts of the 'practice' of running. Looking at the social world through this theoretical lens encourages the researcher to examine how the practice 'fills out the social context' (Schatzki 2017: 130) and 'attributes' mental states to its practitioners (Schmidt, 2017: 151). Rather than framing the interview as a questionable ally in an attempt to understand how patterns of physical movement are acquired and experienced, these ideas encourage us to invert the commonplace idea of action following intention to examine how practices gain strength by attracting some combinations of thought and speech and repelling others (on this see also Schatzki, 2006). We drew upon these ideas in the present study because we were particularly interested in how certain ways of talking and thinking served to secure the continued participation of those who have been running for some time. In terms of the potential for pollution perception, the focus, following this logic, was on how, when and why certain environmental features were welcomed into the thought and the talk of established runners. In this respect, the current lack of consensus about the amount of active consideration given by recreational runners to their surroundings pointed to the potential of our approach. This is because it encouraged us to pay particular attention to how, when and why active consideration happens through the close analysis of which discussion topics were readily taken on by respondents and which proved more challenging.

\subsection{Case study and data collection}


Fourteen participants were interviewed in this study, with individual interviews lasting between 35 and 70 minutes. Though this was a relatively small sample, the aim was to develop the approach through the close examination of how people responded to certain lines of questioning as much as to straightforwardly collect their views. While it is important to recognise this sample cannot therefore represent all recreational runners in London, it did allow the gathering of in-depth knowledge into the individual running experience which was central to this study, rather than making generalisations. The focus was on those who regularly ran outside more than twice a week in London for 30 minutes or over, with at least part of their running happening along the roadside. In London, air pollution is a priority for all local authorities within the city (GLA 2016). However, because London's inner boroughs are thought to have particularly high pollution levels, effort was made to recruit those who ran mostly in inner London, using transport zones 1-3 as a guideline (GLA 2017a).

Participant recruitment started by making contact with running clubs in Westminster and Islington (who specifically ran along the roadside in some of London's most polluted areas). Participants then recommended others, allowing the study to reach those who were not connected with a specific running club. This reduced the potential for indirectly focusing on particular social groups (Valentine 2005). The interviews took place in parks, offices and other quiet places either where participants began or ended their runs or along the routes they often took. One interview took place over the telephone. Participants represented a range of running abilities, from those that trained for triathlons to those who were much less competitive. Although all were recruited on the basis of running for 30 minutes twice a week, this varied from between 30 to 90 minutes at a time, with a mix of long and short runs being common. Table 1 presents an anonymised summary of the sample. 


\begin{tabular}{|c|c|c|c|c|c|c|c|}
\hline $\begin{array}{l}\text { Interview } \\
\text { date }\end{array}$ & Alias & Age & Gender & Occupation & $\begin{array}{l}\text { Number of } \\
\text { runs per } \\
\text { week }\end{array}$ & $\begin{array}{c}\text { How } \\
\text { long } \\
\text { running }\end{array}$ & $\begin{array}{l}\text { Length of time } \\
\text { running in } \\
\text { London }\end{array}$ \\
\hline 17th June & Eloise & $\begin{array}{c}21- \\
30\end{array}$ & Female & Councellor/Play Therapist & $2-3$ & 3 years & 3 years \\
\hline 19th June & Joe & $\begin{array}{l}31- \\
40\end{array}$ & Male & Civil Servant & $\begin{array}{c}6 \text { (8-9 times } \\
\text { when } \\
\text { training) }\end{array}$ & $\begin{array}{c}11 \\
\text { years }\end{array}$ & 7 years \\
\hline 21st June & Arun & $\begin{array}{l}61- \\
70 \\
\end{array}$ & Male & Management Consultant & $3-4$ & $\begin{array}{c}35 \\
\text { years }\end{array}$ & 35 years \\
\hline $\begin{array}{l}\text { 22nd } \\
\text { June }\end{array}$ & Amber & $\begin{array}{c}21- \\
30\end{array}$ & Female & $\begin{array}{c}\text { Communications } \\
\text { Assistant }\end{array}$ & $2-3$ & $\begin{array}{c}15 \\
\text { Years }\end{array}$ & 5 years \\
\hline $\begin{array}{l}\text { 23rd } \\
\text { June }\end{array}$ & Matt & $\begin{array}{c}21- \\
30\end{array}$ & Male & Student & 5 & 6 years & 11 months \\
\hline 26th June & Sophie & $\begin{array}{l}31- \\
40\end{array}$ & Female & Civil Servant & $3-4$ & 4 years & 3 years \\
\hline $\begin{array}{c}\text { 27th June } \\
\text { (by } \\
\text { phone) }\end{array}$ & Alex & $\begin{array}{l}31- \\
40\end{array}$ & Male & Civil Servant & $2-3$ & $\begin{array}{c}24 \\
\text { years }\end{array}$ & 14 years \\
\hline 29th June & Natalie & $\begin{array}{l}21- \\
30\end{array}$ & Female & Civil Servant & $2-3$ & 1 years & 6 months \\
\hline 30th June & Helen & $\begin{array}{l}21- \\
30\end{array}$ & Female & Physiotherapist & $2-3$ & 5 years & 2.5 years \\
\hline 3rd July & Lucy & $\begin{array}{c}21- \\
30\end{array}$ & Female & $\begin{array}{c}\text { Healthcare } \\
\text { Communications Officer }\end{array}$ & $2-4$ & 7 years & 5 years \\
\hline 4th July & Tracey & $\begin{array}{l}51- \\
60 \\
\end{array}$ & Female & Teacher & 3 & $\begin{array}{c}20 \\
\text { years }\end{array}$ & 20 years \\
\hline 5th July & Megan & $\begin{array}{c}21- \\
30\end{array}$ & Female & Physiotherapist & $4-5$ & $\begin{array}{c}10 \\
\text { years }\end{array}$ & 18 months \\
\hline 8th July & Luke & $\begin{array}{l}21- \\
30\end{array}$ & Male & Physiotherapist & $4-5$ & $\begin{array}{c}24 \\
\text { years }\end{array}$ & 9 months \\
\hline 23rd July & Kate & $\begin{array}{l}21- \\
30\end{array}$ & Female & Student & $3-4$ & $\begin{array}{c}10 \\
\text { years }\end{array}$ & 6 years \\
\hline
\end{tabular}

Table 1 - Summary of inteviewees

Interviews began with a series of introductory questions relating to participants' running history and the discussion of a preferred or recent running route. The aim in doing so was not to focus on the experience of specific sessions but rather to encourage participants to begin thinking about their running experiences and the environments they encountered when running. The idea of breathing was then introduced and used to explore how and when they thought about how and what they were breathing. Interviews were recorded and then transcribed to increase familiarity with the data. Initial summaries were made of each interview, noting key themes, thoughts and descriptions, with particular attention being paid within this to moments of breathing awareness and how participants related to their idea of running through potentially polluted air. In view of our conceptual inspirations, extra attention was also given to the ease with which participants discussed different aspects of their breathing with a view to understanding how welcome certain thoughts were, instead 
of collecting sets of 'opinions' that were imagined to exist prior to the interview. Each transcript was then coded thematically using the data analysis tool NVIVO, based on themes drawn from the literature and those developed iteratively through early interview analysis.

\section{RESULTS}

\subsection{Ambivalent about consciousness}

For many respondents, getting their breathing 'right' helped determine the success of a run: 'those first 10 minutes if you can get your breathing right... then it sets you up (Lucy).' However, once a productive rhythm had been established, breathing soon faded into the background unless a disturbance or deliberate change in running style called their attention back to this process. Some respondents took a technical approach by counting breaths or establishing a rhythm between breathing and strides so that they were running in the most effective and efficient ways. However, the aim here was generally to set up a successful breathing strategy and thereafter leave it untroubled by further active reflection.

‘ know that you should breathe probably in a much more...। suppose efficient way than I do. ...If you were going to kind of maximise your breathing pattern's potential ...then you would probably inhale for 4 breaths and then exhale for 4 breaths evenly but...you wouldn't do that naturally.... I think you'd actually have to think about it to do it (Kate).'

As Kate notes, to work on breathing requires individuals to actively 'think' about an otherwise 'unconscious' and 'involuntary' (Edwards 2005:32) process and, as frequent runners, the respondents in this study no longer gave it much thought. Eloise's breathing was noticeable when she first took up running and was 'less aerobically fit'. Thereafter, she gradually became much less aware of it. What was clear in this study was how these runners were often quite adept at talking about breathing in more technical terms, as something which might eventually be 'mastered' or even controlled. Yet we also observed how these abstract ideas were rarely directly connected to their own running practice. Whilst, on the 
one hand, they thought that thinking about their breathing might lead to an improved performance, such thinking was also repelled by the practice after settling into the run.

\subsection{Moments of awareness}

On being probed about occasions of 'breathing awareness', these respondents often pointed to fatigue or particularly tough sections of the run. Mostly this was framed positively as a form of 'healthy breathlessness' (MacNaughton and Carel 2016:302) associated with increasing speed or taking on challenges such as hills. However, several highlighted less positive instances: 'I never run directly past someone with a cigarette...I can feel the effect for a good 10 seconds after l've passed which was quite surprising the first time it happened (Natalie).' Natalie drawing attention to the 'surprise' of noticing suggests she was not used to thinking about her breathing whilst running. Other disruptions included heat, humidity, pollen, smoke and fumes, which were all outlined as environmental features that drew attention to their ability to breathe normally. In considering these experiences, our respondents began to consider the air around them and to question what they inhaled.

When struggling with these issues, breathing was referred to as being 'ragged' (Natalie) or like 'gulping' (Eloise), implying lack of control and, in some rare cases, panic. When things were going better, breathing was considered to be contributing to the more relaxed and 'meditative' (Eloise) experience of running. Breathing was much less dwelled upon in these situations when they were calm and running was more a matter of 'cruising' (Luke) with breathing having enjoyably dipped 'below the threshold' (Luke) of conscious reflection. It was only during moments of sudden disruption that critical consideration of their breathing occurred, and pollution featured as only one of many possible triggers for this. Certainly 'technique' was the register in which these respondents more readily talked of their breathing practice and, within that register, the air, and its potential for variable quality, largely tended to feature as a given, as something too obvious to speak about. 
However, those participants with experience of running in other cities frequently drew on this experience when reaching for answers to questions about London's air quality. This was particularly the case for two who had grown up running in Sydney, Australia. Luke noted very early on in our conversation that he initially struggled with London air pollution:

'I certainly feel just a little bit tighter in the lungs and also if I am pushing hard I will wheeze slightly...That's never actually happened prior to living here which is interesting.' (Luke)

Luke attributes this to London's traffic pollution although admits he sometimes finds this difficult to distinguish from the effect of pollen. Similarly, Megan also commented that she 'never really was averse to roads as much in Australia versus here [London] ...because of population and the number of cars that are on the road.' Experiences elsewhere made these two respondents particularly aware of London air. Developing this point, in the above quote, Luke is looking back on his experience of different bodies of urban air, which at the time encouraged him to choose particular routes. The word choice of 'interesting' is telling and suggests the limited consideration this topic was otherwise given. In this regard, the interview talk that was staged in the study should itself be understood as the creation of a 'critical situation' (Giddens, 1984: 124) in which otherwise routine modes of action became subject to scrutiny, albeit one Luke enjoyed in terms of being encouraged to reflect on a feature of his running practice that generally passed without personal examination.

\section{3 'Fresh air' and its implications}

'I've never really liked gyms because I've always thought exercise should be outside... I kind of think you should get in the fresh air' (Kate).

When discussion turned briefly to indoor treadmill running, the 'gym' was generally framed as a practical option when respondents needed to 'put some hours in' (Matt). It was fine for 
controlled runs when recovering from injury or when dark evenings made outdoor running less appealing. 'Real' running was, however, strongly connected with being 'outside' as a valuable opportunity to spend time outdoors, particularly for those who spent a lot of time working and studying inside. In this regard, there was a strong link between their running and the perceived benefits of being out in the 'fresh air'. Indeed, fresh air was discussed alongside greenery, associated with London's parks and tow paths, as contributing to the most pleasant, relaxing and healthy environments in which to run. However, interestingly these views were more likely to be expressed in terms of why they liked running and what it meant to them, rather than with reference to particular encounters. Running was strongly linked to the idea of 'fresh air' in principle but there were few instances of respondents talking about experiencing it in practice. Indeed, some were wary of speaking of 'fresh air', adding 'for want of a better word' (Lucy) and 'you would hope' (Megan) afterwards. Such caveats suggested they and the practice were keen to keep the positive association in place. Their running was partly sustained by a link to the positive idea of 'fresh' air even if, when asked to think about and discuss it further it, this link was recognised as only 'hopeful'.

Comparisons between running on treadmills in the gym and running outside prompted some to consider the idea of air pollution in terms of the importance of air-flow. The gym was identified as being 'nice and safe' (Amber) in so far as it was removed from street level pollution. When asked to reflect upon it, several runners suggested that the air quality indoors was superior: 'the air is probably better inside I would suspect' (Alex). However, gym air could also be considered to be differently polluted: 'you would be surrounded by this...other people's kind of air and its pollution, so there' $d$ be these really rubbery smells and everything just seemed a bit awful!' (Amber). So, whilst respondents were circumspect about the idea of 'fresh air' when probed about how well it applied to London, the idea was nonetheless so strongly connected to their current practice that strategies for defending this association with reference to poor indoor air could be developed in the interview.

\subsection{The effects of unpleasant experiences}


None of the above is, however, to suggest that these respondents had nothing to say about outdoor air pollution. This was most fully discussed in terms of emissions and fumes that were experienced through noise, sight, taste and smell. Many thought they could 'sense' (Arun) areas where air pollution might be high. Taste and smell particularly featured here:

'I feel like I can, it's almost a taste..., it suddenly gets hotter and thicker and it has like a kind of yuck! Hahaha! ....and I don't know what other symptoms or signs you can look for in terms of recognising pollution, but I do smell and taste it' (Amber).

These experiences were primarily associated with built-up areas and they prompted some to respond by keeping to the inside of the pavement along the roadside, slowing down or sometimes stopping. Seldom, however, did this result in significant changes to route or routine, despite expressing concerns about what they were inhaling at the time. Only a severe reaction would seemingly make them question the value of a run or override the convenience of running in areas close to home or work. And such reactions were rare.

When asked about air quality, it was quite clear that, though responses could certainly be provided to questions, answers were not often drawing on ongoing deliberation. 'Breathing as technique' made for a much easier discussion topic. Though those with asthma or with experiences of breathing impairment related to perceived pollution were better positioned, most had little to say on the matter. This then fed into how discussions about the idea of avoiding polluted areas tended to proceed. In most cases, the link between air quality and route choice was unclear. Where air quality was considered by runners as an influencing factor in their exercise practice (and, in particular, route choice), this often appeared as a retrospective justification. For example, in describing how she avoided running on the road, Tracey noted how it was 'instinctive to avoid those places' due to a combination of noise, traffic and pollution making the roadside 'unpleasant.' Although she spoke of air quality as a reason to avoid certain areas, it did not feature when later discussing factors that might enhance the running experience. Air quality and running were not easily linked. 


\subsection{Protected from pollution}

The effects of poor air quality tended not to be linked to negative impacts on athletic performance by our respondents. They were more often presented as a passing annoyance associated with feelings of discomfort rather than being thought to influence their overall ability to run. Not being able to achieve the best possible running performance was, when this was considered, blamed on personal failings and negative thinking, fatigue or disruption to 'flow' linked to the presence of pedestrians or needing to stop to cross roads. In contrast to the effects of air quality, such matters were discussed far more readily. Views were mixed on whether air pollution really was a risk to them because of their running. The majority did not dismiss the idea. However, most noted that it was more of a passing concern, something they had occasionally 'wondered about' in health impacts terms, rather than something that would stop them exercising. One runner explained how she rationalised the risk:

'Well it's a bit like skin cancer - you know, if you don't wear sun cream you are at risk but you kind of think it's a bit of a tenuous analogy...you can think that...not...not that it won't affect me.... Like it, they do say like on the news that if you have asthma or something then you need to be more aware and I kind of think oh I don't have asthma or bad lungs so I might be ok. Erm, that's probably a bad answer! Ha!'(Lucy).

The idea of a 'bad answer' suggests that Lucy was responding in the moment to a line of thinking that was not part of her existing running practice. Indeed we would argue that our respondents' running practice was partly sustained by not thinking about such matters. Others acknowledged they had a 'denial' (Sophie) or an 'ignorance is bliss' (Eloise) approach to their experience of air quality during running. Although health was clearly a concern, beliefs about the benefits of running were crowding out any thoughts of pollution exposure. In view of how potential health benefits were a key motivation for many in taking up running, the thought that it might also contribute to health problems was understandably unwelcome - they had been drawn to running because of its apparent benefits, after all. 
The contradiction between running as health enhancing and the potential impact of poor air quality was often recognised as challenging in this study. Several respondents stressed their lack of specialist knowledge in terms of knowing the 'biology' (Eloise) behind how exposure linked to health. For us, the question that followed was one of whether or not they wanted to know about these issues. Though pollution was sometimes presented in their talk as a 'frustration' and a 'negative' aspect of London running, on balance 'running always wins' (Amber). The practice of running was insulating them from active thought about pollution effects - the positive ideas by which it was sustained kept pollution out of the picture.

\section{CONCLUSIONS}

Many cities currently face the dual challenge of minimising the public health impacts of air that is often increasingly polluted whilst encouraging increasingly sedentary populations to take part in various forms of physical exercise that still commonly happen outside. In view of this challenge, this paper has presented an original strategy for social researchers hoping to contribute evidence to inform the most effective policy responses. The focus was on how and when regular outdoor recreational runners in London gave any thought to the potentially polluted air that they breathe. Urban recreational runners were taken to be a good case study group for developing this approach in view of the growing international popularity of running and the known effects of pollution exposure linked to city running. In our study, this focus translated into interviews on the experienced breathing of a sample of recreational runners, taking inspiration from social practice theory to examine how their current running practice was partly sustained by certain combinations of thought and talk.

Our results showed that breathing was not often something this group of 'potentially aware' breathers were inclined to think about and that, when they did, considerations were focused on ideas of personal control and effective technique more often than avoiding pollution exposure. We also discussed the times when breathing became laboured, along 
with how various environmental conditions played into this experience. Though air pollution risks were recognised within this, they did not greatly feature and they rarely translated into amended actions. Route choice, for example, was most strongly influenced by convenience and the avoidance of disruption. Air pollution featured as one aspect that might feed into this, but it often only appeared in our conversations as a retrospective justification. It was only among those who had experienced highly negative experiences such as breathlessness or wheezing who admitted air pollution was a key consideration into their route planning process. This then took us to how 'air' was talked about more broadly to examine how, the strength of the association between running, health and 'fresh air' was such that it repelled any negative ideas about pollution from attaching themselves to their running practice.

In developing our approach, we made links between a range of existing research topics. These include those associated with environmental relations in recreational running, those associated with the methods and theories used to research the embodied experience of exercise, and those associated with the means by which breathing can be productively examined through a cultural lens. However, in conclusion we want particularly to highlight the implications of our study for public health promotion and pollution perception research.

In terms of public health promotion, we want to begin by noting how certain transformative experiences, such as relocating to London, did prompt reflection on the quality of air these respondents were breathing. There may therefore be opportunities for interventions that centre on moments when air quality is already entering into the consciousness of those who are inclined to run in cities by catching them at the points when they are most open to the idea of avoiding polluted areas. However, more generally this study reveals the challenge of encouraging established recreational runners to avoid or protect themselves from urban air pollution. For these participants, air pollution was generally given little consideration and was often rather unwelcome in their thoughts. Furthermore, despite many participants being able to connect breathing difficulties and poor air quality, air quality was not thought to impact upon their overall athletic performance. They liked the idea of improving their performance, but they couldn't change the general quality of the air so there was little point 
to thinking about it. The link between running as an activity with positive health benefits as well as providing the opportunity to be outside in the 'fresh air' was also so strong that it effectively sealed our respondents inside a protective mental bubble that repelled the idea of negative pollution effects. In view of how it is through long term exposure that urban air pollution causes significant health problems (Brunekreef and Holgate 2002) that these runners did not develop a more responsive relationship between route choice and the varied levels of air pollution found outdoors in London is concerning. However, it is also true that the health benefits of outdoor exercise generally still outweigh the damage associated with pollution exposure (on this see, for example, Tainio et al. 2016). Viewed in this way, we could feel more positive about the how their running practice insulated our respondents from negative thoughts about pollution effects and thereby persist with a beneficial activity.

In terms of air pollution perception research, on the occasions when the runners in this study considered pollution, this was largely through taste and smell. This supports the argument for rooting this research in the sensory experience of everyday life (Bickerstaff 2004). Beyond that, the chief broader contribution of the presented approach relates to how it sheds light on how the 'perception gap' (Bickerstaff and Walker 2001:142) whereby individuals are aware of pollution risk but don't think that it applies to them, is established and sustained over the lifetime of their participation in relevant social practices. As we argued earlier, existing qualitative studies of air pollution perception are characterised by a recurring focus on the resident. Though this has its merits, by starting with practices, rather than places, we put ourselves in a position to provide a different understanding of the issue. Further studies in this vein might look to the ways in which outdoor exercise practices form and mutate in cities with very different pollution profiles to London. In this respect, the present study particularly points to the potential of studies comparing those at different stages of their practice careers in terms of how the idea of pollution exposure may be differently received by those who are comparatively new to particular activities and places and those who have a more longstanding relationship with them. Future researchers might also usefully examine the relationship between experienced breathing and air pollution perception amongst those who participate in other outdoor activities beyond exercise. In terms of how this empirical work is practically organised, we recognise that gaining an 
understanding of how existing practices respond to the idea of variable air quality might be a challenge in view of how this idea is often put aside as a subject of active reflection in everyday life. However, this paper suggests that paying careful attention to how relevant practitioners verbally respond to relevant topics, could be an effective strategy for taking it on. Either way, we conclude that further in-depth studies with a starting focus on what people do, rather than where they live, stand to provide original insights for this field.

\section{REFERENCES}

Allen-Collinson, J. 2008. Running the routes together: corunning and knowledge in action. Journal of Contemporary Ethnography, 37, 38-61.

Allen-Collinson, J., Owton, H., Crust, L., 2016. Opening up dialogues and airways: using vignettes to enrich asthma understandings in sport and exercise. Qualitative Research in Sport, Exercise and Health, 8, 352-364

Andrews, G., 2017. 'Running hot': Placing health in the life and course of the vital city. Social Science and Medicine, 175, 209-214

Badland, H., Duncan, M., 2009. Perceptions of air pollution during the work-related commute by adults in Queensland, Australia. Atmospheric Environment, 43, 5791-5795

Barnfield, A., 2016. Public health, physical exercise and non-representational theory - a mixed method study of recreational running in Sofia, Bulgaria. Critical Public Health, 26, 281-293

Bickerstaff, K., 2004. Risk perception research: socio-cultural perspectives on the public experience of air pollution. Environment International, 30, 827-840

Bickerstaff, K., Walker, G., 2001. Public understandings of air pollution: the 'localisation' of environmental risk. Global Environmental Change, 11, 133-145

Bourdieu, P., 1990. In other words. Stanford University Press, Stanford California

Brunekreef, B., Holgate, S., 2002. Air pollution and health. The Lancet. 360, 1233-1242

Carlisle, A., Sharp, N., 2001. Exercise and outdoor ambient air pollution. British Journal of Sports Medicine, 35, 214-222

Cavalcante de Sá, M., Nakagawa, N., Saldiva de André, C., Carvalho-Oliveira, R., de Santana Carvalho, T., Nicola, M., de André, P., Nascimeto Saldiva,P., Vaisberg, M., 2016. Aerobic exercise in polluted urban environments: effects on airway defense mechanisms in young healthy amateur runners. Journal of Breathing Research, 10, 1-9

Cook, S., Shaw, J., Simpson, P., 2016. Jography: Exploring Meanings, Experiences and Spatialities of Recreational Road-running. Mobilities, 11, 744-769 
D’Amato, G., Cecchi, L., D’Amato, M., Liccardi, G., 2010. Urban air pollution and climate change as environmental risk factors of respiratory allergy: an update. Journal of Investigational Allergology and Clinical Immunology, 20, 95-102

Day, R., 2007. Place and the experience of air quality. Health and Place, 13, 249-260 de Hartog J., Boogaard H., Nijland H., Hoek G., 2010. Do the Health Benefits of Cycling Outweigh the Risks? Environmental Health Perspectives, 118, 1109-1116

Department of Health, 2011. Start Active, Stay Active: report on the physical activity for health from the four home countries' Chief Medical Officers. Department of Health, London

Edensor, T., Kärrholm M, Wirdelöv, J., 2018. Rhythmanalysing the urban runner:

Pildammsparken, Malmö. Applied Mobilities, in press.

Edwards, S., 2005. A Psychology of Breathing Methods. International Journal of Mental Health Promotion. 7, 30-36

England Athletics, 2013. A Nation that Runs: a recreational running and athletics plan for England 2013-2017. England Athletics, Birmingham

England Athletics, 2017. Athletics and Running: For everyone, forever. Strategic Plan: 2017. England Athletics, Birmingham

Giddens, A., 1984. The Constitution of Society: Outline of the Theory of Structuration. University of California Press, California

Greater London Authority, 2016. Mayor's Air Quality Fund: Supporting Local Action on Air Quality 2013-2016. GLA.

Greater London Authority, 2017a. London's Toxic Air. GLA.

Greater London Authority, 2017b. London Environment Strategy: Draft for Public Consultation (Executive Summary) GLA

Griffin, M. 2017. Embodied learning and new physical activity in mid- and later life, Qualitative Research in Sport, Exercise and Health, 9, 554-567

Helou, N., Tafflet, M., Berthelot, G., Tolaini, J., Marc, A., Guillaume, M., Haussworth, C., Toussaint, J., 2012. Impact of Environmental Parameters on Marathon Running Performance PLoS ONE, 7, 1-9

Hitchings, R., Latham, A., 2016. Indoor versus outdoor running: understanding how recreational exercise comes to inhabit environments through practitioner talk. Transactions of the Institute of British Geographers, 41, 503-514

Hitchings, R., Latham, A., 2017a. Exercise and environment: New qualitative work to link popular practice and public health. Health and Place, 46, 300-306

Hitchings, R., Latham, A., 2017b. How 'social' is recreational running? Findings from a qualitative study in London and implications for public health promotion. Health and Place, 46, 337-343

Hockey, J., 2013. Knowing the 'Going': the sensory evaluation of distance running. Qualitative Research in Sport, Exercise and Health, 5, 127-141 
Howe, P., Morris, C., 2009. An exploration of the co-production of performance running bodies and natures within "Running Taskscapes." Journal of Sport and Social Issues, 33, 308330

Hui, A., Schatzki, T., Shove, E. (eds) 2017. The Nexus of Practices: Connections, constellations, practitioners. London: Routledge.

Johnson, B., 2012. Experience with Urban Air Pollution in Paterson, New Jersey and Implications for Air Pollution Communication. Risk Analysis, 32, 39-53

Kumate, J., Falcous, M., 2017. Grappling with judo: reflections on the complexities of embodied ethnography. Qualitative Research in Sport, Exercise and Health, 9, 200-213

Lande, B., 2007. Breathing like a soldier: culture incarnate. Sociological Review. 55, 95-108

Li, J., Pearce, P., Morrison, A., Wu, B., 2016. Up in Smoke? The Impact of Smog on Risk Perception and Satisfaction of International Tourists in Beijing. International Journal of Tourism Research, 18, 373-386

London Air Quality Network (2017) London Air: Advice on exercise in London. https://www.londonair.org.uk/LondonAir/guide/Exercise.aspx (Accessed 11 February 2018)

London Air Quality Network (2018) Is air pollution worse in London? https://www.londonair.org.uk/LondonAir/guide/London.aspx (Accessed 8 May 2018)

Lorimer, H., 2012. Surfaces and Slopes. Performance Research, 17, 83-86

Lundby, C., Millet, G., Calbet, J., Bartsch, P., Subudhi, A., 2012. Does 'altitude training' increase exercise performance in elite athletes? British Journal of Sports Medicine, 46, 792795

Macnaughton, J., Carel, H., 2016. Breathing and breathlessness in clinic and culture: using critical medical humanities to bridge an epistemic gap, in: Whitehead, A., Woods, A., [Eds] The Edinburgh Companion to the Critical Medical Humanities. Edinburgh University Press, Edinburgh. 294-309

McKenna, J., Riddoch, C., 2003. Perspectives on health and exercise. Palgrave, Basingstoke Muindi, K., Egondi, T., Kimani-Murage, E., Rocklov, J., Ng, N. 2014. "We are used to this": a qualitative assessment of and attitudes towards air pollution amongst slum residents in Nairobi. BMC Public Health, 14, 226

Nyberg, G., 2015. Developing a 'somatic velocimeter': the practical knowledge of free skiers. Qualitative Research in Sport, Exercise and Health, 7, 488-503

Owton, H., Allen-Collinson, J., 2017. 'It stays with you': multiple evocative representations of dance and future possibilities for studies in sport and physical cultures. Qualitative Research in Sport, Exercise and Health, 9, 49-55

Oxley, R. Macnaughton, J. 2016. Inspiring change: humanities and social science insights into the experience and management of breathlessness. Current Opinion in Supportive and Palliative Care, 10, 256-261

Pope, CA., Burnett, R., Turner, M., Cohen, A., Krewski, D., Jerrett, M., Gapstur, S., Thun, M. 2011. Lung Cancer and Cardiovascular Disease Mortality Associated with Ambient Air Pollution and Cigarette Smoke: Shape of the Exposure-Response Relationships.

Environmental Health Perspectives, 119, 1616-1621 
Rundell, K., 2012. Effect of air pollution on athlete health and performance. British Journal of Sports Medicine, 46, 407-412

Rusko, H., Tikkanen, H., Peltonen, J., 2004. Altitude and endurance training. Journal of Sports Sciences, 22, 928-945

Saksena, S., 2011. Public Perceptions of Urban Air Pollution Risks. Risks, Hazards and Crisis in Public Policy. 2, 1-19

Schatzki, T., 1996. Social practices: a Wittgensteinian approach to human activity and the social Cambridge University Press, Cambridge

Schatzki, T., 2017. Sayings, texts and discursive formations. In Hui, A., Schatzki, T., Shove, E. (eds). The Nexus of Practices: Connections, constellations, practitioners. London: Routledge. 126-140

Scheerder, J., Breedveld, K., Borgers, J., 2015. Running Across Europe: The Rise and Size of one of the Largest Sports Markets, Palgrave Macmillan, London

Schmidt (2017) Reflexive Knowledge in Practices in Hui, A., Schatzki, T., Shove, E. (eds). The Nexus of Practices: Connections, constellations, practitioners. London: Routledge. 141-154

Schücker, L., Hagemann, N., Strauss, B., Volker, K., 2009. The effect of attentional focus on running economy. Journal of Sports Sciences, 27, 1241-1248

Sharman, J., Cockcroft, J., Coombes, J., 2004. Cardiovascular implications of exposure to traffic air pollution during exercise. QJM: An international Journal of Medicine. 97, 637-643

Shipway, R., Holloway, I., 2010. Running free: Embracing a healthy lifestyle through distance running. Perspectives in Public Health, 130, 270-276

Shipway, R., Holloway, I., Jones, I., 2012. Organisations, practices, actors, and events: Exploring inside the distance running social world. International Review for the Sociology of Sport, 43, 259-276

Sport England, 2017. Active Lives Survey 2015-16: Year 1 Report.

Tainio, A., de Nazelle, A., Götschi, T., Kahlmeier, S., Rojas-Rueda, D., Nieuwenhuijsen, M., Hérick de Sá, T., Kelly, P., Woodcock, J. 2016. Can air pollution negate the health benefits of cycling and walking? Preventive Medicine, 87, 233-236

Valentine, G. 2005. Tell me about: using interviews as a research methodology in Flowerdew, R. and Martin, D. [eds] Methods in human Geography: Second Edition, London: Routledge, 110-126

Wacquant, L., 2004. Body and soul. Oxford University Press, Oxford

Wakefield, S., Elliott, S., Cole, D., Eyles, J., 2001. Environmental risk and (re)action: air quality, health, and civic involvement in an urban industrial neighbourhood. Health and Place, 7, 163-177

WHO (2016) Ambient (outdoor) air quality and health.

Xu, J., Chi, C., Zhu, K., 2017. Concern or apathy: the attitude of the public toward urban air pollution. Journal of Risk Research, 30, 482-498 
Zhang, L., Yuan, Z., Maddock, J., Zhang, P., Jiang, Z., Lee, T., Zou, J., Lu, Y., 2014. Air quality and environmental protection concerns among residents in Nanchang, China. Air Quality, Atmosphere and Health, 7, 441-448

Zuurbier M., Hoek G., Oldenwening M., Lenters V., Meliefste K., van den Hazel,P., Brunekreef, B., 2010. Commuters' Exposure to Particulate Matter Air Pollution Is Affected by Mode of Transport, Fuel Type, and Route. Environmental Health Perspectives, 118, 783-789 